\title{
ANALYTICAL SOLUTIONS TO THE STREAM-AQUIFER INTERACTION PROBLEM: A CRITICAL REVIEW
}

\author{
K. SPANOUDAKI* \\ A. NANOU-GIANNAROU \\ Y. PASCHALINOS \\ C.D. MEMOS \\ A.I. STAMOU
}

Received: 03/04/09

Accepted: 24/02/10

\author{
Laboratory of Applied Hydraulics, \\ Department of Water Resources and Environmental \\ Engineering, School of Civil Engineering, \\ National Technical University of Athens (NTUA), \\ Iroon Polytechniou 5, 15780 Athens, Greece
}

*to whom all correspondence should be addressed: e-mail: kspan@central.ntua.gr

\section{ABSTRACT}

The aim of the present paper is to give a systematic and critical presentation of important existing analytical solutions for transient stream-aquifer interaction, which can be used to give answers to simple interaction problems or to verify mathematical models. Stream-aquifer interaction is the most common subject of papers discussing surface water-ground water interaction and a review of analytical solutions to the problem is lacking from the literature. The analytical solutions presented in the paper are firstly distinguished based on whether only the ground water flow equations or both the ground water and stream flow equations are solved for their derivation and secondly based on the type of aquifer (confined or unconfined) interacting with the stream and on the type of equations solved. The literature review showed that there is only a small number of publications, where the authors consider both the ground water and the stream flow equations for the development of the analytical solutions. The majority of the available analytical solutions of stream-aquifer interaction are derived by solving only the ground water flow equations, taking into account the stream water level as a boundary condition.

For each analytical solution presented in the paper, its accuracy, its ease of application to simple interaction problems and its suitability for the verification of mathematical models are discussed in detail. Specifically for the case of predicting the water table level in unconfined aquifers interacting with streams, an analytical solution of the non-linear Boussinesq equation is compared to two analytical solutions of different linearized forms of the Boussinesq equation, in order to quantify the error in estimating the water table level when using a linear solution. Among the very few analytical solutions found in the literature, where the authors consider both the stream flow and ground water flow equations for their development, the most comprehensive one is chosen to give an application example, which can be used as a benchmark case for the verification of integrated stream-aquifer mathematical models.

KEYWORDS: stream-aquifer interaction, analytical solutions, ground water flow, stream flow.

\section{INTRODUCTION}

Surface water and ground water are not isolated components of the hydrologic cycle. Instead, all surface water bodies are often hydraulically connected to ground water and the interaction between them affects both their quantity and quality. In the past few decades, increased demand for water associated with population growth has heightened environmental awareness and with it the realization that effective management of the limited water resources requires a realistic quantification of the interaction between surface water and ground water (Courbis et al., 2008; Ma et al., 2008).

Until the advent of computers, analytical solutions used to be the only computational method available to quantify surface water-ground water interaction. The limitation of the analytical solutions is that they are applicable to simplified or idealized cases. Today, with the evolution of computers, we have the possibility to develop and use sophisticated mathematical models for the solution of 
complex interaction problems, in regard to geometry, boundary conditions and aquifer hydraulic properties and developing analytical solutions is commonly seen as cumbersome and limiting (Haitjema 2006). However, analytical solutions to interaction problems are important and should not be seen as something from the past because: (a) their application is straightforward and is the simplest and quickest way to obtain answers for simple interaction cases, (b) they give good insight into the dependence of the solution variable on the state variables and therefore improve our understanding of the physical processes occurring within an interacting surface water-ground water system, (c) they provide a means of validating the mathematics of a numerical solution and (d) they can be used to estimate aquifer hydraulic properties, e.g. hydraulic diffusivity (Halkidis et al., 2009).

The aim of this paper is to give a systematic and critical presentation of an array of important analytical solutions of stream-aquifer interaction, which can be used to give answers to simple interaction problems or to verify mathematical models. Stream-aquifer interaction is the most common subject of papers discussing surface water-ground water interaction and a review of analytical solutions to the problem is lacking from the literature. In the present paper, only solutions for transient stream-aquifer interaction are analyzed, as including the large number of existing steady state solutions would take far more space than available here. Furthermore, steady state solutions are well-documented in popular textbooks (e.g. Polubarinova-Kochina, 1962; Harr, 1962). The analytical solutions presented in the paper are distinguished based on whether only the ground water flow equations or both the ground water and stream flow equations are solved for their derivation. The majority of the available analytical solutions of stream-aquifer interaction are derived by solving only the ground water flow equations. The stream water level fluctuations are assumed to be known a priori and are used as a boundary condition for the solution of the ground water flow equations. Only a very small number of publications is found in the literature, where the authors consider both sets of equations in the development of the analytical solutions (e.g. Hunt, 1990; Lal, 2001; Hantush et al., 2002). The analytical solutions presented in the paper are further distinguished based on the type of aquifer interacting with the stream and on the type of equations solved for their development. Their advantages and limitations are discussed in detail. An application example is given for an analytical solution, derived by solving the coupled stream flow and ground water flow equations, which is found by the authors more suitable for the verification of mathematical models.

\section{ANALYTICAL SOLUTIONS OF STREAM-AQUIFER INTERACTION: SOLUTION OF THE GROUND WATER FLOW EQUATIONS}

\subsection{Confined aquifers}

The literature review showed that the problem of quantifying the interaction between a stream and a confined aquifer is usually reduced to solving the homogeneous or the non-homogeneous 1-D diffusion equation for various boundary conditions. The 1-D diffusion equation can be solved using a number of mathematical methods. The most common is to use Laplace transforms, as described by Carslaw and Jaeger (1959) for the solution of problems of heat conduction. For boundary conditions, which vary sinusoidally in time, the steady periodic solution of the 1-D diffusion equation is usually obtained assuming that it takes the form of a combination of sines and cosines or that it can be represented by the real part of a complex variable (Pipes and Harvill, 1970).

The general case of stream-confined aquifer interaction considered by most authors is shown in Figure 1. A horizontal, semi-infinite or of finite width, homogeneous and isotropic aquifer is bounded at one end by a fully penetrating stream with or without semipervious banks. The implicit assumption is made that the semipervious stream banks have no storage. The aquifer has a constant thickness and an impermeable base. Ground water flow is assumed 1-D horizontal in the $\mathrm{x}$ direction and is described by the homogeneous diffusion equation (1) with the appropriate initial and boundary conditions (equations (2) to (4b)). 


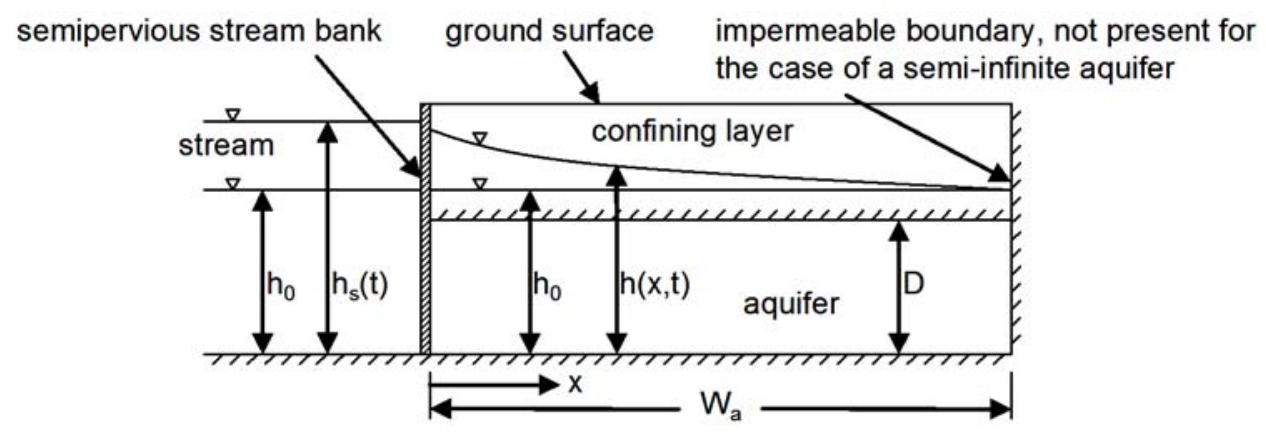

Figure 1. Stream-confined aquifer interaction schematic

$\frac{\partial^{2} \mathrm{~h}(\mathrm{x}, \mathrm{t})}{\partial \mathrm{x}^{2}}=\frac{1}{\sigma} \frac{\partial \mathrm{h}(\mathrm{x}, \mathrm{t})}{\partial \mathrm{t}}$

$h(x, 0)=h_{0}$

$h(0, t)=h_{s}(t)$ for a stream without semipervious banks

$\frac{\partial h(0, t)}{\partial x}=\frac{1}{a}\left[h(0, t)-h_{s}(t)\right]$ for a stream with semipervious banks

$\lim _{x \rightarrow \infty} h(x, t)=h_{0}$ for a semi-infinite aquifer

$\frac{\partial \mathrm{h}\left(\mathrm{W}_{\mathrm{a}}, \mathrm{t}\right)}{\partial \mathrm{x}}=0$ for an aquifer of finite width

In equations (1) to (4b) $h(x, t)[L]$ is the piezometric head, $\sigma\left[L^{2} T^{-1}\right]$ is the aquifer hydraulic diffusivity defined as $\sigma=T / S$, where $T\left[L^{2} T^{-1}\right]$ is the aquifer transmissivity and $S[-]$ is the aquifer storage coefficient, $h_{s}(t)[L]$ is the stream water level, $h_{0}$ is the initial value of piezometric heads in the aquifer, which coincides with the initial stream water level and $a[L]$ is the retardation coefficient as defined by Hantush (1965) equal to $a=K_{b} b / K$, where $K\left[L^{-1}\right]$ is the aquifer hydraulic conductivity and $\mathrm{K}_{\mathrm{b}}\left[\mathrm{LT}^{-1}\right]$ and $\mathrm{b}[\mathrm{L}]$ are the hydraulic conductivity and the thickness, respectively, of the semipervious stream bank. The retardation coefficient describes the resistance to flow imparted by the semipervious bank. This resistance may alternatively be viewed as the effective width of aquifer with no storage, required to cause the same piezometric head loss as the semipervious stream bank.

Hantush (1961) developed solutions for the piezometric heads in a semi-infinite aquifer for a linear variation of the stream water level with time. A solution for the steady periodic response of the piezometric heads in a semi-infinite aquifer subject to a sinusoidal variation of the stream water level was presented by Ferris (1963). Cooper and Rorabaugh (1963) derived solutions for the piezometric heads, the seepage at the stream-aquifer interface and the bank storage, for the case of a symmetrical or asymmetrical flood wave at the stream and a semi-infinite or of finite width aquifer. Probably the most widely applied solutions are those of Hall and Moench (1972) for the response of the piezometric heads in a semi-infinite or of finite width aquifer to a unit step change of the stream water level. The authors also provided analytical solutions for the seepage at the stream-aquifer interface. Hall and Moench (1972) were the first to examine the case of a stream with semipervious banks. As far as the solution method is concerned, Cooper and Rorabaugh (1963) used Laplace transforms to derive the expressions for the aquifer responses. The solutions presented in Hantush (1961), Ferris (1963) and Hall and Moench (1972) were obtained from the solution of analogous problems of heat conduction (Carslaw and Jaeger, 1959; Ingersoll et al., 1948).

Singh (2004) extended previous works by considering, for the first time, the effect of both stream partial penetration and semipervious bed and banks on aquifer responses. He derived analytical expressions for the piezometric heads, the flow rate and the volume of flow in a horizontal, infinite, homogeneous and isotropic aquifer for the following stream water level variations: (a) sinusoidal, (b) linear, (c) a unit step change and (d) a symmetrical flood wave. Singh (2004) simplified the solution of the actual problem (Figure 2 (a)) by considering the equivalent idealized case of a fully penetrating stream (Figure 2 (b)). He introduced an additional hypothetical aquifer width, R, with no storage, required to cause the same piezometric head loss as the stream partial penetration and 
semipervious bed and banks. Assuming 1-D ground water flow in the $x$ direction, the idealized problem can be described by equations (1), (2), (3b) and (4a), if the retardation coefficient, $a$, is replaced by $\mathrm{R}$. Singh (2004) obtained analytical solutions to the problem, for the different stream water level variations, from the solution of analogous problems of heat conduction (Carslaw and Jaeger, 1959).

Parameters $a$ and $R$, as defined in the previous paragraphs, are used to account for stream resistance to flow. The difference between them is that $R$ includes the resistances due to both the semipervious bed and partial penetration of the stream. Therefore, $R$ can be expressed as $R=a+R_{p}$, where $R_{p}$ is the resistance due to stream partial penetration (Singh, 2003). It is important to note that there is no equation available for estimating $R_{p}$. Singh (2003 and 2004) suggests that the value of $R$ can be obtained from field measurements through minimization of the errors between the measured and analytically computed piezometric heads.

Singh's (2004) analytical solutions are the most comprehensive of those that have been published for semi-infinite confined aquifers; analytical solutions presented in previous works can be obtained as special cases of Singh's solutions. In more detail: (a) if $R=0$ (i.e. fully penetrating stream having no semipervious bed) is put in Singh's analytical expressions for aquifer responses to a symmetrical flood wave and to a linear variation of the stream water level, one gets the expressions given by Cooper and Rorabaugh (1963) and by Hantush (1961), respectively, (b) Singh's solution for a unit step change of the stream water level coincides with the solution of Hall and Moench (1972), if $R$ is replaced by $a$ and (c) for large values of time and for $R=0$, Singh's solution for a sinusoidal variation of the stream water level reduces to the steady periodic solution of Ferris (1963). The drawback in applying Singh's solutions for predicting aquifer responses in simple interaction cases or for verifying mathematical models is that there is no equation available for estimating R. However, Singh's analytical solutions are useful in estimating aquifer hydraulic diffusivity, $\sigma$ and stream resistance to flow, $\mathrm{R}$, from field measurements of piezometric heads.
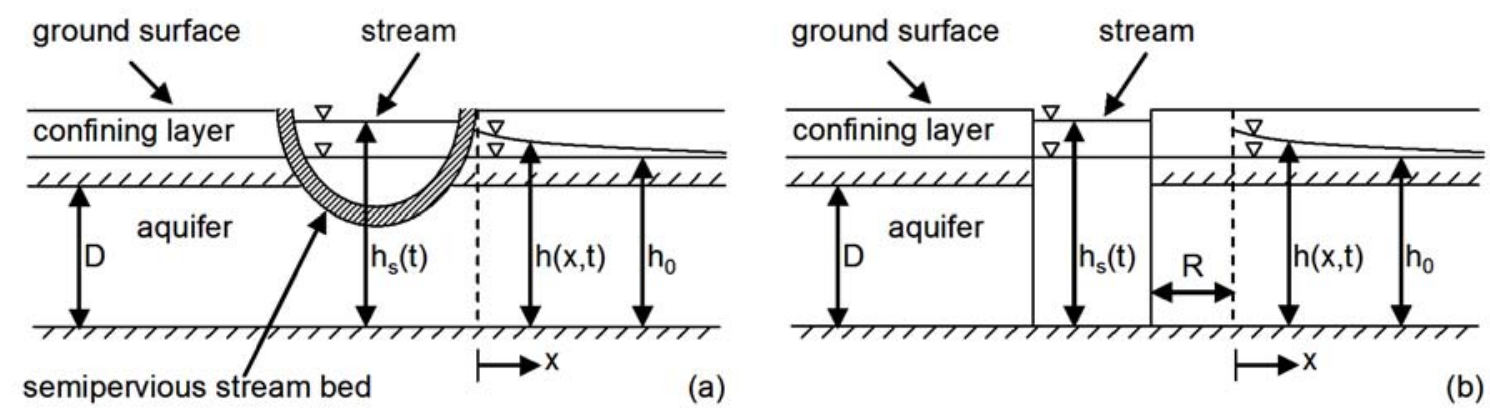

Figure 2. Schematic of the stream-confined aquifer interaction problem considered by Singh (2004):

(a) actual problem and (b) idealized problem

A very interesting work is that of Townley (1995), who presented a methodology for obtaining the response of the piezometric heads in a homogeneous and isotropic confined aquifer of finite width, to boundary conditions, which vary sinusoidally in time. Townley (1995) obtained the steady periodic solution of the non-homogeneous 1-D diffusion equation (5), assuming that it can be represented by the real part of a complex variable (Pipes and Harvill, 1970).

$\frac{\partial^{2} \mathrm{~h}(\mathrm{x}, \mathrm{t})}{\partial \mathrm{x}^{2}}+\frac{\mathrm{W}(\mathrm{t})}{\mathrm{T}}=\frac{1}{\sigma} \frac{\partial \mathrm{h}(\mathrm{x}, \mathrm{t})}{\partial \mathrm{t}}$

In equation (5) $\mathrm{W}(\mathrm{t})\left[\mathrm{LT}^{-1}\right]$ represents distributed recharge or evapotranspiration. The author presented the solution in a general form, which can be applied for any boundary conditions (Dirichlet, Neuman or Cauchy), provided, of course, that at least one of them or the recharge/evapotranspiration varies sinusoidally in time. Townley (1995) gave application examples of the general solution for the following cases: (a) impermeable boundary at $x=0$ (Neumann boundary condition), fully penetrating stream with sinusoidally varying water level at $x=W_{a}$ (Dirichlet boundary condition) and $\mathrm{W}(\mathrm{t})=0,(\mathrm{~b})$ impermeable boundary at $\mathrm{x}=0$, fully penetrating stream with constant water level at $x=W_{a}$ and $W(t)$ varying sinusoidally with time and (c) impermeable boundary at $x=0$, fully penetrating stream with semipervious banks and sinusoidally varying water level at $\mathrm{x}=\mathrm{W}_{\mathrm{a}}$ (Cauchy boundary condition) and $\mathrm{W}(\mathrm{t})$ varying sinusoidally in time. 
Analytical solutions of the ground water flow equations for ideal boundary conditions such as step, linear or sinusoidal stream water level fluctuations are useful for understanding the transient response of ground water systems to stream water level changes. However, stream water level usually varies arbitrarily in time. For such cases the convolution method can be used for obtaining the aquifer responses. Convolution is a form of superposition. It uses the response of a linear system to an impulse or a unit step input, to simulate the effect of arbitrary input with the help of convolution integrals (Hall and Moench, 1972). Since the stream water level is usually measured at discrete time intervals, the convolution integrals are expressed in a discretized form and are solved numerically (Hall and Moench, 1972).

A comprehensive discussion of the use of the convolution method in stream-aquifer studies is given by Hall and Moench (1972). Barlow et al. (2000) used convolution integrals to estimate aquifer responses to an arbitrary stream water level for the same interaction cases considered by Hall and Moench (1972). The treatment for an arbitrary stream water level has also been addressed by Singh (2004), who used pulse kernels and ramp kernels to solve the convolution integrals. Singh (2004) found that the use of ramp kernels for obtaining the convolution integral gives superior results than the use of conventional numerical integration or pulse kernels.

\subsection{Unconfined aquifers}

Two approaches have been used to derive analytical solutions for flow in unconfined aquifers interacting with streams. The first approach assumes 1-D horizontal ground water flow in a homogeneous and isotropic aquifer. The second approach treats ground water flow as 2-D in the vertical $x-z$ plane.

The interaction cases considered in the first approach are illustrated in Figure 3. The aquifer can be semi-infinite or of finite width, bounded at one end by a fully penetrating stream with or without semipervious banks (Figure 3 (a)). The problem of a finite-width aquifer bounded by two fully penetrating streams with no semipervious banks (Figure 3 (b)), has also been examined by many researchers. In Figure $3, h_{0}(x)$ is used to describe the initial ground water table level across the aquifer, i.e. $h(x, 0)=h_{0}(x)$. Under the assumption of a homogeneous and isotropic aquifer, 1-D horizontal ground water flow is described by the Boussinesq equation:

$\frac{\partial}{\partial x}\left(h(x, t) \frac{\partial h(x, t)}{\partial x}\right)+\frac{W(x, t)}{K}=\frac{S_{y}}{K} \frac{\partial h(x, t)}{\partial t}$

where $S_{y}[-]$ is the aquifer specific yield.
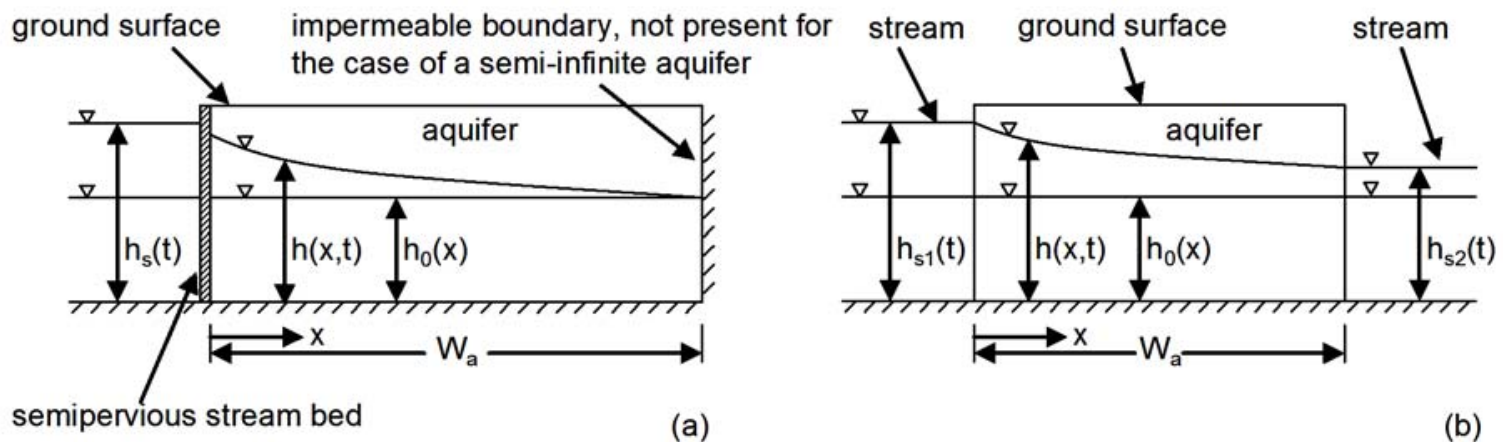

(a)

(b)

Figure 3. Schematic of stream-unconfined aquifer interaction cases where ground water flow is considered 1-D horizontal

The Boussinesq equation (6) is a non-linear partial differential equation and therefore, its analytical solution is cumbersome. Serrano and Workman (1998) used the decomposition method (Adomian, 1994) to develop an analytical solution of the Boussinesq equation for the case shown in Figure 3 (b). Their work is the only one found in the literature, where the non-linear Boussinesq equation is solved to estimate stream-aquifer interaction. In all other publications, where 1-D horizontal flow in a homogeneous and isotropic aquifer is considered, one of the linearized forms (7a) or (7b) of equation (6) is solved. 


$$
\begin{aligned}
& \frac{\partial^{2} h(x, t)}{\partial x^{2}}+\frac{W(x, t)}{\bar{T}}=\frac{S_{y}}{\bar{T}} \frac{\partial h(x, t)}{\partial t} \\
& \frac{\partial^{2} h^{2}(x, t)}{\partial x^{2}}+\frac{2 W(x, t)}{K}=\frac{S_{y}}{\bar{T}} \frac{\partial h^{2}(x, t)}{\partial t}
\end{aligned}
$$

In (7a) and (7b) $\overline{\mathrm{T}}$ represents a mean value of transmissivity defined as $\overline{\mathrm{T}}=\mathrm{K} \overline{\mathrm{h}}$, where $\overline{\mathrm{h}}$ is a mean value for the aquifer saturated thickness. A summary of publications, where either the non-linear or one of the linearized forms of the Boussinesq equation is solved to estimate stream-aquifer interaction, is given in Table 1.

Clearly the most accurate solution of those presented in Table 1 is that of Serrano and Workman (1998), which is applicable even in cases of large changes in the ground water table level. For such cases analytical solutions of the linearized forms (7a) or (7b) of the Boussinesq equation may not give accurate results. To assess the performance of the linear solutions, the analytical solutions of Serrano and Workman (1998), Ostfeld et al. (1999) and Workman et al. (1997) have been applied to an interaction problem with the following characteristics: $W_{a}=200 \mathrm{~m}, K=50 \mathrm{~m}^{-1 a y}{ }^{-1}, S_{y}=0.3, h_{0}(x)=1$ $m$ and $W(x, t)=0.02 \mathrm{~m} \mathrm{day}^{-1}$. At time $t=0+\varepsilon$, where $\varepsilon$ is an infinitesimally small number, the water level of the left stream was instantaneously raised from $1 \mathrm{~m}$ to $5 \mathrm{~m}$ and remained constant thereafter, i.e. $h_{s 1}(t)=5 \mathrm{~m}$. The water level of the right stream was held constant at $1 \mathrm{~m}$, i.e. $\mathrm{h}_{\mathrm{s} 2}(\mathrm{t})=1 \mathrm{~m}$.

Figure 4 shows a comparison of the water table levels predicted using the solutions of Ostfeld et al. (1999) and Workman et al. (1997) with the water table predicted using the solution of Serrano and Workman (1998). In applying the solutions of Ostfeld et al. (1999) and Workman et al. (1997), three different approaches have been used to estimate a mean value for the aquifer saturated thickness: (a) $\bar{h}$ was assumed equal to the initial water table level $h_{0}$, (b) $\bar{h}$ was defined as the average between the initial and steady state water table levels across the aquifer, designated by havg and (c) $\bar{h}$ was taken equal to the average of the lowest and highest water table levels, denoted by $h_{\min } \max$. As it can be seen in Figure 4, among the two linear solutions, the solution of Ostfeld et al. (1) $\overline{9} 99)$ gives results, which are closer to the non-linear solution of Serrano and Workman (1998). This is due to the difference in linearization of the Boussinesq equation. Equation (7a) is obtained from the non-linear Boussinesq equation (6) by treating $h(x, t)$ inside the first space differential operator as a constant, with the assumption of small water table fluctuations compared to the mean saturated thickness of the aquifer. In deriving equation (7b), on the contrary, $h(x, t)$ is treated as a variable, which is in better agreement with the non-linear Boussinesq equation. Another advantage of equation (7b) over (7a) is that for steady flow equation (7b) remains non-linear.

Figure 5 shows the mean relative errors between the solutions of Ostfeld et al. (1999) and Workman et al. (1997) and the solution of Serrano and Workman (1998) for various sets of boundary conditions; $h_{\max }$ in the figure refers to the maximum water table level obtained at steady state. As expected, the error increases as the water table level change increases. The solution of Ostfeld et al. (1999) is superior to the solution of Workman et al. (1997) and the best estimate for $\bar{h}$ seems to be $h_{\text {avg. }}$.

It is important to note that apart from the solutions referenced in Table 1, the analytical solutions presented in paragraph 2.1 for confined aquifers can also be applied to unconfined aquifers, under the assumption that changes of the water table level are small compared to the mean saturated thickness of the aquifer, since equation $(7 a)$ is similar to the non-homogeneous 1-D diffusion equation (5) if $S_{y}$ is substituted by $S$ and $\bar{h}$ by $D$. 
Table 1. Publications where the 1-D Boussinesq equation or one of its linearized forms is solved to estimate stream-aquifer interaction

\begin{tabular}{|c|c|c|c|c|}
\hline Reference & Equation & $\begin{array}{l}\text { Initial } \\
\text { conditions }\end{array}$ & $\begin{array}{l}\text { Boundary } \\
\text { Conditions }\end{array}$ & Solution method \\
\hline \multirow[t]{2}{*}{ Marino (1973) } & $(7 b)$ with $W(x, t)=0$ & $h(x, 0)=h_{0}$ & $\begin{array}{l}(3 a) \text { or }(3 b) \\
(4 a) \text { or }(4 b)\end{array}$ & $\begin{array}{l}\text { Laplace } \\
\text { transforms }\end{array}$ \\
\hline & & & $\mathrm{h}_{\mathrm{s}}(\mathrm{t})=\left\{\begin{array}{l}\mathrm{h}_{0}, \mathrm{t}=0 \\
\mathrm{~h}_{0}+\Delta \mathrm{h}, \mathrm{t}>0\end{array}\right.$ & \\
\hline \multirow[t]{2}{*}{$\begin{array}{l}\text { Govindaraju } \\
\text { and Koelliker } \\
(1994)\end{array}$} & (7a) with $\mathrm{W}(\mathrm{x}, \mathrm{t})=0$ & $h(x, 0)=h_{0}(x)$ & $\lim _{x \rightarrow \infty} h(x, t)=\lim _{x \rightarrow \infty} h_{0}(x)$ & $\begin{array}{l}\text { Laplace } \\
\text { transforms and } \\
\text { convolution }\end{array}$ \\
\hline & & & $\begin{array}{l}\mathrm{h}_{\mathrm{s}}(\mathrm{t}) \text { can vary arbitrarily } \\
\text { with time }\end{array}$ & integrals \\
\hline $\begin{array}{l}\text { Workman et } \\
\text { al. (1997) }\end{array}$ & $\begin{array}{l}\text { (7a) with } \\
W(x, t)=\text { constant }\end{array}$ & $\mathrm{h}(\mathrm{x}, 0)=\mathrm{h}_{0}(\mathrm{x})$ & $\begin{array}{l}\mathrm{h}(0, \mathrm{t})=\mathrm{h}_{\mathrm{s} 1}(\mathrm{t}) \\
\mathrm{h}\left(\mathrm{W}_{\mathrm{a}}, \mathrm{t}\right)=\mathrm{h}_{\mathrm{s} 2}(\mathrm{t})=\text { constant } \\
\mathrm{h}_{\mathrm{s} 1}(\mathrm{t}) \text { can vary arbitrarily } \\
\text { with time }\end{array}$ & $\begin{array}{l}\text { Variable } \\
\text { separation } \\
\text { method }\end{array}$ \\
\hline $\begin{array}{l}\text { Kim and Ann } \\
\text { (2001) }\end{array}$ & $\begin{array}{l}\text { (7a) with } \\
W(x, t)=\text { constant }\end{array}$ & $\mathrm{h}(\mathrm{x}, 0)=\mathrm{h}_{0}(\mathrm{x})$ & $\begin{array}{l}\mathrm{h}(0, \mathrm{t})=\mathrm{h}_{\mathrm{s} 1}(\mathrm{t})=\text { constant } \\
\mathrm{h}\left(\mathrm{W}_{\mathrm{a}}, \mathrm{t}\right)=\mathrm{h}_{\mathrm{s} 2}(\mathrm{t})=\text { constant }\end{array}$ & $\begin{array}{l}\text { Variable } \\
\text { separation } \\
\text { method }\end{array}$ \\
\hline $\begin{array}{l}\text { Ostfeld et al. } \\
\text { (1999) }\end{array}$ & $\begin{array}{l}(7 \mathrm{~b}) \text { with } \mathrm{W}(\mathrm{x}, \mathrm{t}) \\
\text { given by an } \\
\text { analytic function }\end{array}$ & $h(x, 0)=h_{0}(x)$ & $\begin{array}{l}h(0, t)=h_{s 1}(t) \\
h\left(W_{a}, t\right)=h_{s 2}(t) \\
h_{s 1}(t), h_{s 2}(t) \text { are given by } \\
\text { analytic functions }\end{array}$ & $\begin{array}{l}\text { Laplace } \\
\text { transforms }\end{array}$ \\
\hline $\begin{array}{l}\text { Serrano and } \\
\text { Workman } \\
\text { (1998) }\end{array}$ & $\begin{array}{l}\text { (6) with } \\
W(x, t)=\text { constant }\end{array}$ & $\mathrm{h}(\mathrm{x}, 0)=\mathrm{h}_{0}(\mathrm{x})$ & $\begin{array}{l}h(0, t)=h_{s 1}(t) \\
h\left(W_{a}, t\right)=h_{s 2}(t) \\
h_{s 1}(t), h_{s 2}(t) \text { can vary } \\
\text { arbitrarily with time }\end{array}$ & $\begin{array}{l}\text { decomposition } \\
\text { method }\end{array}$ \\
\hline
\end{tabular}

The second approach of deriving analytical solutions for unconfined aquifers by treating ground water flow as 2-D in the vertical x-z plane was taken by Higgins (1980), Neuman (1981), van de Giessen et al. (1994), Moench and Barlow (2000), Barlow et al. (2000) and Serrano (2003). Higgins (1980) considered the case of a horizontal, semi-infinite, homogeneous and isotropic aquifer bounded by a fully penetrating stream with no semipervious banks. Initially the water table level was assumed horizontal and the stream water level equal to the water table level. Ignoring elastic storage effects, i.e. assuming the aquifer material is rigid and the water is incompressible, as usually done for unconfined flow, ground water flow is described by the 2-D Laplace equation:

$\frac{\partial^{2} h(x, z, t)}{\partial x^{2}}+\frac{\partial^{2} h(x, z, t)}{\partial z^{2}}=0$

Time enters the problem through the kinematic boundary condition at the free surface, which after linearization and expanding it in a Taylor series about the initial water table level $h_{0}$ (assuming that water table level fluctuations are small compared to the initial saturated thickness of the aquifer $h_{0}$ ) can be written as:

$\frac{\partial \mathrm{h}\left(\mathrm{x}, \mathrm{h}_{0}, \mathrm{t}\right)}{\partial \mathrm{z}}=-\frac{\mathrm{S}_{\mathrm{y}}}{\mathrm{K}} \frac{\partial \mathrm{h}\left(\mathrm{x}, \mathrm{h}_{0}, \mathrm{t}\right)}{\partial \mathrm{t}}$

Higgins (1980) obtained a solution for the piezometric heads $h(x, z, t)$, for a step change of the stream water level, using the variable separation method. 

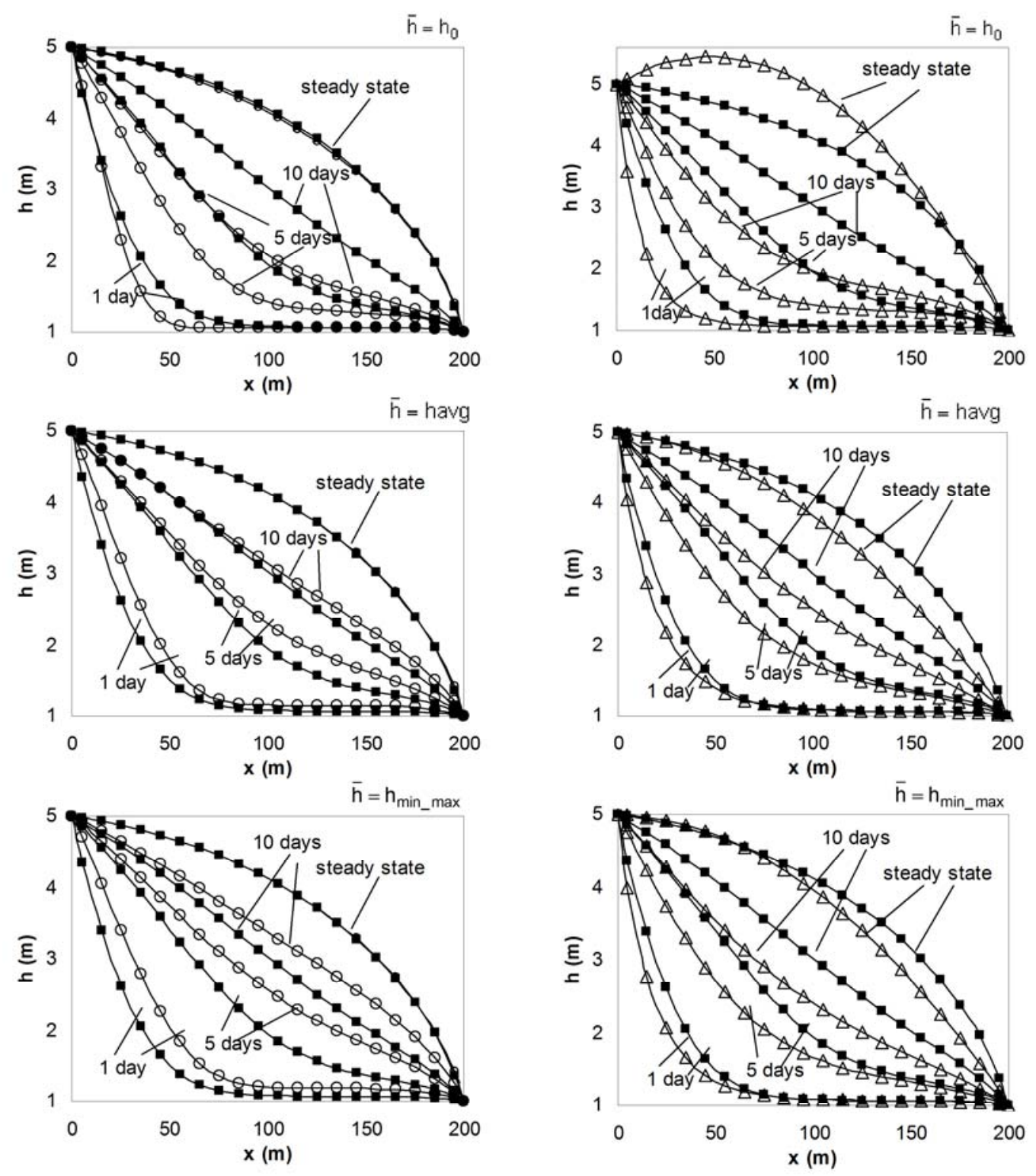

$\rightarrow-$ Serrano and Workman (1998) - - Ostfeld et al. (1999) $\triangle$-Workman et al. (1997)

Figure 4. Water table levels predicted with the analytical solutions of Ostfeld et al. (1999), Workman et al. (1997) and Serrano and Workman (1998)

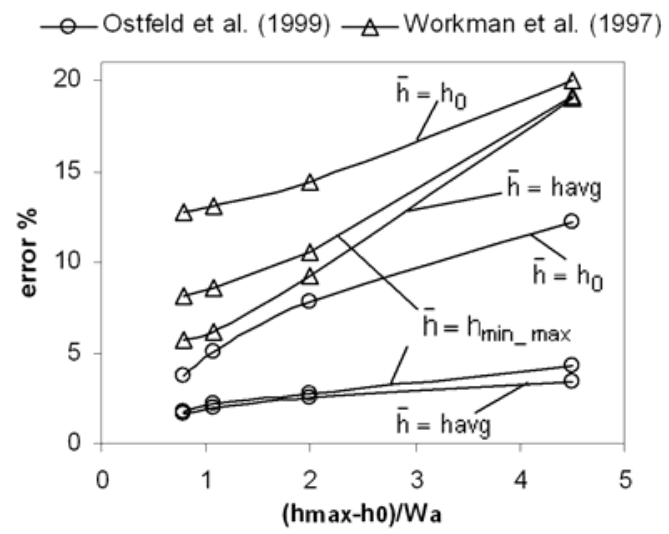

Figure 5. Mean relative errors between the solutions of Ostfeld et al. (1999) and Workman et al. (1997) and the solution of Serrano and Workman (1998) 
Neuman (1981) extended the work of Higgins (1980) by accounting for elastic storage and considering the aquifer to be anisotropic. In this case equations (8) and (9) become:

$$
\begin{aligned}
& \mathrm{K}_{\mathrm{x}} \frac{\partial^{2} \mathrm{~h}(\mathrm{x}, \mathrm{z}, \mathrm{t})}{\partial \mathrm{x}^{2}}+\mathrm{K}_{\mathrm{z}} \frac{\partial^{2} \mathrm{~h}(\mathrm{x}, \mathrm{z}, \mathrm{t})}{\partial \mathrm{z}^{2}}=\mathrm{S}_{\mathrm{s}} \frac{\partial \mathrm{h}(\mathrm{x}, \mathrm{z}, \mathrm{t})}{\partial \mathrm{t}} \\
& \frac{\partial \mathrm{h}\left(\mathrm{x}, \mathrm{h}_{0}, \mathrm{t}\right)}{\partial \mathrm{z}}=-\frac{\mathrm{S}_{\mathrm{y}}}{\mathrm{K}_{\mathrm{z}}} \frac{\partial \mathrm{h}\left(\mathrm{x}, \mathrm{h}_{0}, \mathrm{t}\right)}{\partial \mathrm{t}}
\end{aligned}
$$

where $\mathrm{K}_{\mathrm{x}}$ and $\mathrm{K}_{\mathrm{z}}$ are the hydraulic conductivities in the $\mathrm{x}$ and $\mathrm{z}$ directions, respectively. Neuman (1981) used Laplace transforms to obtain a solution for $h(x, z, t)$.

Van de Giessen et al. (1994) took an approach similar to Higgins (1980) but for a finite-width aquifer, bounded by two fully penetrating streams with no semipervious banks, with their water level variations being given by analytic functions. The authors made use of a Fourier series and eigenfunction expansion (Haberman, 1987) to solve the 2-D Laplace equation (8) for the appropriate initial and boundary conditions.

Moench and Barlow (2000) presented Laplace-transform step response functions for the same interaction problem considered by Neuman (1981), taking additionally into account the stream semipervious banks. They also presented step response functions for a finite-width aquifer bounded at one end by a fully penetrating stream with or without semipervious banks and at the other end by an impermeable boundary. The Laplace domain solutions can be numerically inverted to the realtime domain with the Stehfest (1970) algorithm. In the companion paper of Barlow et al. (2000) the step response functions were used in convolution integrals to derive aquifer responses to an arbitrarily varying stream water level.

Serrano's (2003) analytical solution is the most comprehensive of those that have been published for unconfined aquifers. He considered an anisotropic aquifer of finite width, bounded by two fully penetrating streams with no semipervious banks, with the stream water level fluctuations described by analytic functions. Serrano (2003) ignored elastic storage effects and was the first to consider the non-linear form of the kinematic boundary condition at the moving free surface:

$$
\frac{\partial h\left(x, z_{w t}, t\right)}{\partial t}+\frac{K_{z}+W(t)}{S_{y}} \frac{\partial h\left(x, z_{w t}, t\right)}{\partial z}-\frac{K_{x}}{S_{y}}\left(\frac{\partial h\left(x, z_{w t}, t\right)}{\partial x}\right)^{2}-\frac{K_{z}}{S_{y}}\left(\frac{\partial h\left(x, z_{w t}, t\right)}{\partial z}\right)^{2}=\frac{W(t)}{S_{y}}
$$

where $z_{w t}$ denotes the water table level. The author used the decomposition method (Adomian, 1994) to derive a solution for the piezometric heads $h(x, z, t)$ and the water table level. Unlike previous solutions for 2-D vertical unconfined flow, Serrano's (2003) analytical solution has the advantage of being applicable even in cases of large changes in the ground water table level. However, it requires an estimate of the initial distribution of piezometric heads $h_{0}(x, z)$ and of the vertical gradient near the free surface, which is not always possible.

\section{ANALYTICAL SOLUTIONS OF STREAM-AQUIFER INTERACTION: SOLUTION OF THE COUPLED STREAM FLOW AND GROUND WATER FLOW EQUATIONS}

Only four publications, those of Hunt (1990), Hantush et al. (2002), Hantush (2005) and Lal (2001), have been found in the literature, where both the stream flow and groundwater flow equations are considered in the development of the analytical solutions. Hunt (1990) used a perturbation procedure to derive an approximate solution that couples the kinematic wave equation for stream flow to 1-D horizontal unconfined ground water flow, normal to the stream flow direction, described by the linearized Boussinesq equation. The stream was assumed to be in perfect hydraulic connection with the aquifer, which could be of finite or infinite width. Hunt's (1990) solution has a relatively simple form and is easily applied.

Hantush et al. (2002) examined the stream-unconfined aquifer interaction problem shown in Figure 6 (a). The aquifer was assumed homogeneous and isotropic, infinite in the $x$ direction and bounded by impermeable boundaries in the y direction. Stream flow was approximated using a simple mass balance equation and the Muskingum linear storage relationship and groundwater flow was approximated by the 1-D, in the $x$ direction, linearized Boussinesq equation. Hantush et al. (2002) used Laplace transforms and convolution integrals to derive solutions for the stream discharge and the seepage at the stream aquifer interface due to an arbitrary stream inflow hydrograph. The work of Hantush et al. (2002) was extended by Hantush (2005) who took into account (a) aquifer recharge 
or evapotranspiration and (b) hillslope runoff during storm events or evaporation from the stream surface during inter-storm periods.

Lal (2001) considered the case of stream-aquifer interaction shown in Figure 6 (b). The domain is infinite in the $x$ direction and semi-infinite in the $y$ direction. The aquifer was assumed homogeneous and isotropic, separated from the stream by its semipervious bed and banks. Ground water flow was assumed 2-D horizontal, described by the linearized Boussinesq equation for an unconfined aquifer or the diffusion equation for a confined aquifer. Stream flow was assumed 1-D, described by the diffusion wave approximation to the Saint Venant equations. The estimation of seepage at the stream-aquifer interface was based on Darcy's law. Lal (2001) used a perturbation procedure to solve the system of equations describing stream flow, ground water flow and seepage at the streamaquifer interface for a small amplitude sinusoidal variation of the stream water level. Lal's (2001) solution is more comprehensive than the solutions of Hunt (1990), Hantush et al. (2002) and Hantush (2005). Hence it is indicated for the verification of integrated stream-aquifer models.
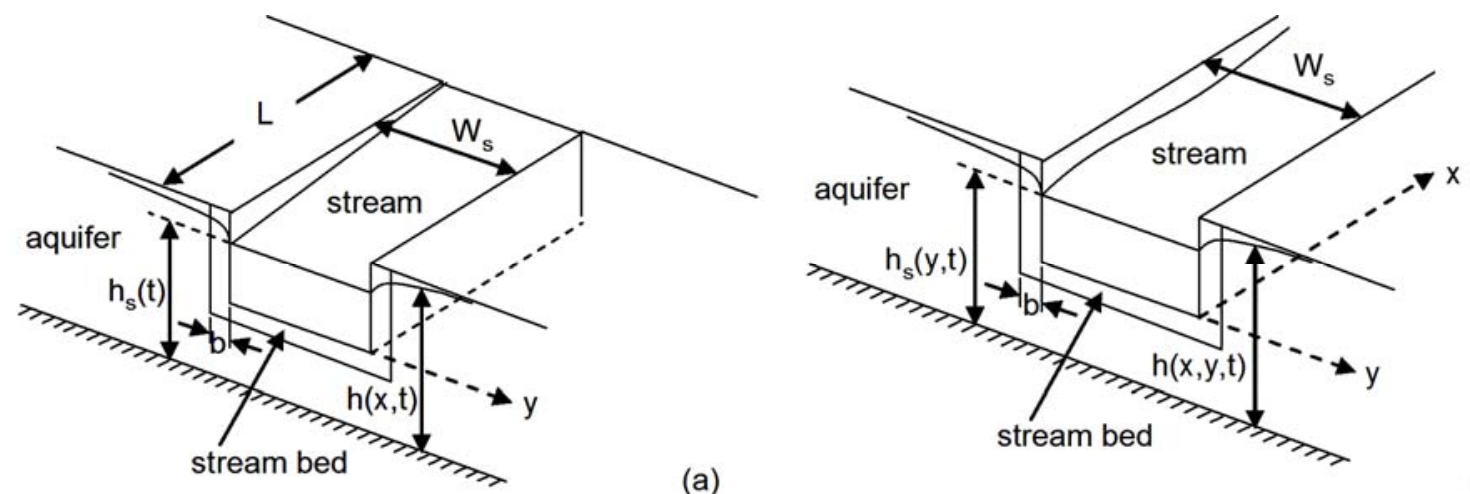

(a)

Figure 6. Stream-aquifer interaction cases considered (a) by Hantush et al. (2002) and (b) by Lal (2001)

An application example of Lal's solution is given here, which can be used as a benchmark case for the verification of integrated models. To demonstrate the application of a model for this example, the integrated surface water-groundwater model IRENE (Spanoudaki et al., 2005; Spanoudaki et al., 2006 ) is used. In the example, the aquifer is considered confined with a transmissivity of $T=0.05 \mathrm{~m}^{2}$ $\mathrm{s}^{-1}$ and a storage coefficient of $S=0.15$. The stream, which has a width of $W_{s}=30 \mathrm{~m}$ and a bed slope of $S_{0}=10^{-5}$, flows on top of the confined aquifer, i.e. the stream penetration depth into the aquifer, $d$, is equal to zero and seepage between the stream and the aquifer occurs from the stream bed alone, which has a thickness of $b=0.5 \mathrm{~m}$ and a hydraulic conductivity of $K_{b}=0.0007 \mathrm{~m} \mathrm{~s}^{-1}$. Initially, the water depth in the stream is assumed equal to the uniform flow water depth $\mathrm{H}_{0}=4.0 \mathrm{~m}$ computed from Manning's equation for a discharge rate of $q_{0}=1.064 \mathrm{~m}^{2} \mathrm{~s}^{-1}$, using a Manning's roughness coefficient value of $n=0.03 \mathrm{~m}^{-1 / 3} \mathrm{~s}$. The stream is initially in hydraulic equilibrium with the aquifer, i.e. $h(x, y, 0)=h_{s}(y, 0)$ or $h_{0}(x, y)=h_{s 0}(y)$. At $t=0$, a continuous sinusoidal variation of the stream water level is introduced at the upstream boundary $(y=0)$. The variation has the form: $h_{s}(0)=h_{s 0}(0)+\alpha \sin (2 \pi t / T)$; the amplitude of the variation is $\alpha=1.0 \mathrm{~m}$ and the period of the variation is $\mathrm{T}=5 \mathrm{hrs}$.

Lal (2001) expressed the solutions for the stream water level and the piezometric heads as:

$h_{s}(y, t)=h_{s 0}(y)+\alpha \exp (f t+\lambda y)$ and $h(x, y, t)=h_{0}(x, y)+\alpha \exp [f t+\lambda y+\theta b+\mu(x-b)]$

where $f, \lambda, \mu$ and $\theta$ are complex constants, $f=f_{1}+f_{2} i, \lambda=\lambda_{1}+\lambda_{2} i, \mu=\mu_{1}+\mu_{2} i$ and $\theta=\theta_{1}+\theta_{2} i$, in which $\lambda_{1}, \mu_{1}$ represent the amplitude decay rate constants and $\lambda_{2}, \mu_{2}$ the wave numbers for the stream water level and the piezometric heads variations along the stream and the aquifer, respectively, $\theta=\mu T /\left[0.5\left(2 d+W_{s}\right) K_{b}\right]$ and $f_{1}, f_{2}$ are the time decay constant and the frequency, respectively, of the variation introduced at the upstream boundary. For the application example discussed here, $f_{1}=0$ and $f_{2}=2 \pi / T$. The complex constants $\lambda$ and $\mu$ are obtained from the solution of the system of equations (14) where the unknown variables, explained in Table 2, are estimated from the data of the application example. The estimated values for $\lambda, \mu$ and $\theta$ are also shown in Table 2 . 
$\frac{\mu}{\Lambda}=-\sqrt{\frac{i}{P_{r}}-\left(\frac{\Lambda}{\Lambda}\right)^{2}}$ and $\frac{\lambda}{\Lambda}=\frac{1}{2 P_{d}}-\sqrt{i+\frac{1}{4 P_{d}{ }^{2}}-2 \frac{\mu P_{r}}{\Lambda P_{b}} \exp \left(\frac{P_{r} \mu}{P_{m} \Lambda}\right)}$

In order to apply IRENE to the example, the length of the stream and the aquifer in the $y$ direction is selected as $L=50000 \mathrm{~m}$ and the aquifer width in the $x$ direction as $W_{a}=500 \mathrm{~m}$. Using the analytical solution of Lal (2001) it is estimated that for $y \geq 40000 \mathrm{~m}$ and $\mathrm{x} \geq 235 \mathrm{~m}$ the piezometric heads in the aquifer are only slightly affected by the sinusoidal variation of the stream water level. Therefore, the dimensions selected satisfy the infinite domain requirement of the analytical solution. The hydraulic conductivity of the aquifer is taken as $K=0.001 \mathrm{~m} \mathrm{~s}^{-1}$ and the aquifer thickness as $D=50 \mathrm{~m}$ at the upstream boundary and $D=49.5 \mathrm{~m}$ at the downstream boundary, to follow the slope of the stream bed. All aquifer boundaries are considered impermeable. At $t=0$ the sinusoidal variation is introduced at the upstream boundary and IRENE is run until steady periodic state is reached. A comparison of the results of the analytical solution and IRENE for the stream water level variation along the stream and the piezometric heads variation across the aquifer is shown in Figure 7.
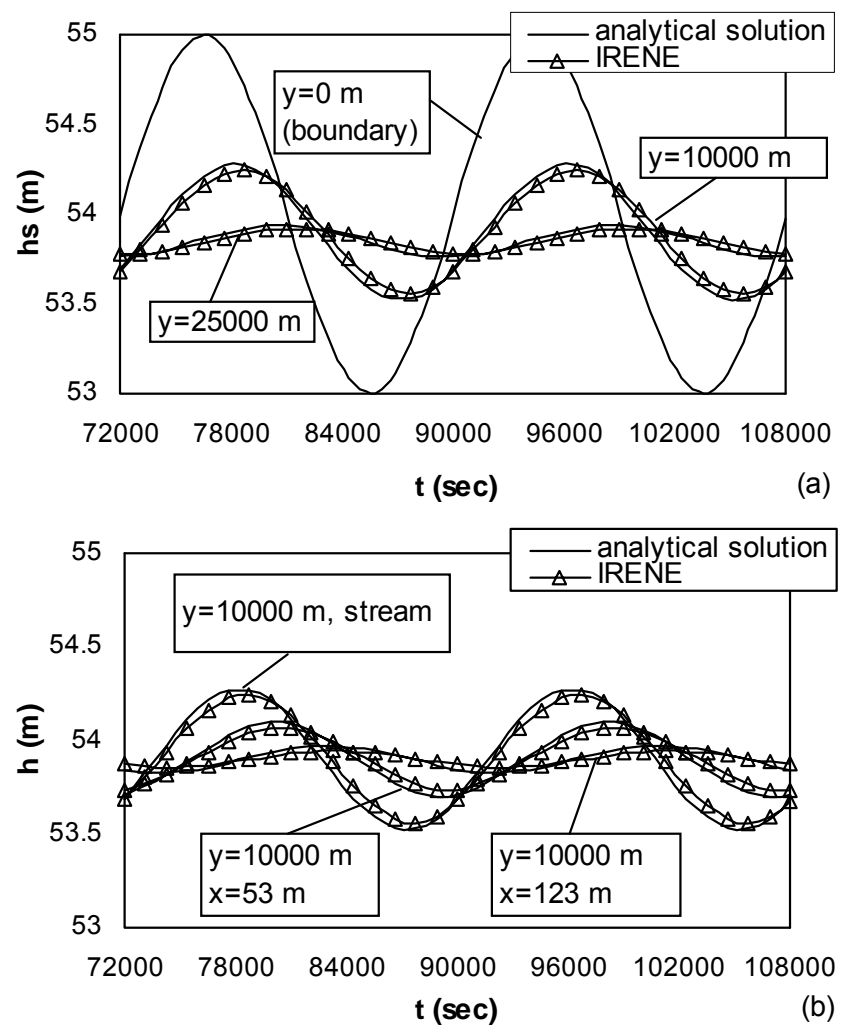

Figure 7. Comparison of the results of the analytical solution of Lal (2001) and IRENE:

(a) variation of the stream water level for $y=10000 \mathrm{~m}$ and $\mathrm{y}=25000 \mathrm{~m}$ and

(b) variation of the piezometric heads across the aquifer for $y=10000 \mathrm{~m}$

Table 2. Parameter values used for the application of the solution of Lal (2001)

\begin{tabular}{lll}
\hline Variable & Explanation & Value \\
\hline$\Lambda$ & characteristic length & $12350 \mathrm{~m}$ \\
\hline$P_{\mathrm{r}}$ & transmissivity ratio parameter & $3.131 \times 10^{-5}$ \\
\hline$P_{\mathrm{b}}$ & stream width parameter & 0.016 \\
\hline$P_{\mathrm{d}}$ & stream depth parameter & 9.717 \\
\hline$P_{\mathrm{m}}$ & stream resistance parameter & 0.065 \\
\hline$\lambda_{1}$ & amplitude decay rate constant along the stream & -0.952 \\
\hline$\lambda_{2}$ & wave number for the stream water level variation & -0.715 \\
\hline$\mu_{1}$ & amplitude decay rate constant along the aquifer & -126.37 \\
\hline$\mu_{2}$ & wave number for the piezometric heads variation & -126.37 \\
\hline$\theta_{1}$ & & -0.233 \\
\hline$\theta_{2}$ & & -0.233 \\
\hline
\end{tabular}




\section{CONCLUSIONS}

In this paper a critical review of important existing analytical solutions for transient stream-aquifer interaction is presented. The majority of the available analytical solutions are obtained by solving the equations, which describe ground water flow in the stream-aquifer system, while the stream flow equations are ignored; the stream water level fluctuations are considered to be known a priori and are used as a boundary condition for the solution of the ground water flow equations. Only four publications have been found in the literature, where the authors consider both the stream flow and the ground water flow equations in the development of the analytical solutions.

The literature review showed that the problem of deriving analytical solutions for the interaction between a stream and a confined aquifer is usually reduced to solving the homogeneous or the nonhomogeneous 1-D diffusion equation for various boundary conditions such as a step change, a linear or a sinusoidal variation of the stream water level. Singh's (2004) analytical solutions are the most comprehensive of those that have been published for confined aquifers and take into account the effect of both stream partial penetration and semipervious bed and banks on aquifer responses. The drawback in applying these solutions is that there is no equation available for estimating the stream resistance to flow.

Analytical solutions for flow in unconfined aquifers interacting with streams are derived following two approaches. The first approach assumes 1-D horizontal ground water flow in a homogeneous and isotropic aquifer. In this case the 1-D Boussinesq equation describes ground water flow and is usually linearized prior to its solution. The work of Serrano and Workman (1998) is the only one found in the literature, where the non-linear Boussinesq equation is solved to estimate streamaquifer interaction. The second approach treats ground water flow as 2-D in the $x-z$ plane. In most publications following this approach, the kinematic boundary condition at the free surface is linearized about the initial water table level. This introduces the limitation of small water table fluctuations compared to the initial saturated thickness of the aquifer. Serrano (2003) is the only author who considered the non-linear form of the kinematic boundary condition at the moving free surface. Therefore, its solution has the advantage of being applicable even in cases of large changes in the ground water table level.

In the papers where both the stream flow and ground water flow equations are considered, ground water flow is assumed 1-D or 2-D horizontal, described by the linearized Boussinesq equation. Stream flow is in most cases approximated by the kinematic wave equation or using a simple mass balance equation and the Muskingum linear storage relationship. The most comprehensive solution is that of Lal (2001) who coupled the diffusion wave approximation to the Saint Venant equations with 2-D linearized Boussinesq equation for ground water flow.

The authors find that, among the available analytical solutions of stream-aquifer interaction, the solutions of Serrano and Workman (1998) and Serrano (2003) are the most suitable for testing the ability of a model to predict the transient ground water table level and the solution of Lal (2001), being the most elaborate, is suitable for verifying the results of integrated stream-aquifer models for both the stream water level and the piezometric heads variations.

\section{ACKNOWLEDGEMENTS}

The work presented in this paper is part of the NTUA Program for Basic Research Lefkippos: 'Theoretical and experimental investigation of surface water-ground water interaction'.

\section{REFERENCES}

Adomian G. (1994), Solving Frontier Problems in Physics-The Decomposition Method, Kluwer Academic, Dordrecht.

Barlow P.M., De-Simone L.A. and Moench A.F. (2000), Aquifer response to stream-stage and recharge variations. II. Convolutions method and applications, Journal of Hydrology, 230(3-4), 211-229.

Carslaw H.S. and Jaeger J.C. (1959), Conduction of heat in solids, Second Edition, Oxford University Press, London.

Courbis A.L., Vayassade B., Martin C. and Didon-Lescot J.F. (2008), Modelling and simulation of a catchment in order to evaluate water resources, Global NEST J., 10(3), 301-309.

Cooper-Jr.H.H. and Rorabaugh M.I. (1963), Ground-water movements and bank storage due to flood stages in surface streams, USGS Water-Supply Paper 1536-J, pp. 343-366.

Dumm L.D. (1954), Drain-spacing formula, Agricultural Engineering, 35(10), 726-730. 
Ferris J.G. (1963), Cyclic water-level fluctuations as a basis for determining aquifer transmissibility', in: 'Methods of determining permeability, transmissibility and drawdown, USGS Water-Supply Paper 1536-I, pp. 305-318.

Govindaraju R.S. and Koelliker J.K. (1994), Applicability of the linearized Boussinesq equation for modeling bank storage under uncertain parameters, Journal of Hydrology, 157(1-4), 349-366.

Haberman R., (1987), Elementary applied partial differential equations, Prentice-Hall, Englewood Cliffs, New Jersey.

Haitjema H. (2006), The role of hand calculations in ground water flow modeling, Ground Water, 44(6), 786-791.

Halkidis I.N., Tzimopoulos C.D., Evangelides C.H. and Sakellariou-Markantonaki M. (2009) Soil water management problem using fuzzy arithmetic, Global NEST J., 11(4), 556-565.

Hall F.R. and Moench A.F. (1972), Application of the convolution equation to stream-aquifer relationships, Water Resources Research, 8(2), 487-493.

Hantush M.S. (1961), Discussion of paper by P.P. Rowe, An equation for estimating transmissibility and coefficient of storage from river-level fluctuations, Journal of Geophysical Research, 66(4), 13101311.

Hantush M.S. (1965), Wells near stream with semipervious beds, Journal of Geophysical Research, 70(12), 2829-2838.

Hantush M.M. (2005), Modeling stream-aquifer interactions with linear response functions, Journal of Hydrology, 311, 59-79.

Hantush M.M., Harada M. and Marino M.A. (2002), Hydraulics of stream flow routing with bank storage, Journal of Hydrologic Engineering, 7(1), 76-89.

Harr M.E. (1962), Groundwater and seepage, McGraw-Hill Book Company, New York.

Higgins D.T. (1980), Unsteady drawdown in 2-D water table aquifer, Journal of the Irrigation and Drainage Division, 106(IR3), 237-251.

Hunt B. (1990), An approximation for the bank storage effect, Water Resources Research, 26 (11), 27692775.

Ingersoll L.R., Zobel O.J. and Ingersoll A.C. (1948), Heat conduction with engineering and geological applications, McGraw-Hill Book Company, New York.

Kim D.J. and Ann M.J. (2001), Analytical solutions of water table variation in a horizontal unconfined aquifer: Constant recharge and bounded by parallel streams, Hydrological Processes, 15(13), 26912699.

Lal A.M.W. (2001), Modification of canal flow due to stream-aquifer interaction, Journal of Hydraulic Engineering, 127(7), 567-576.

Ma S., Kassinos S.C., Kassinos D.F. and Akylas E. (2008), Modeling the impact of water withdrawal schemes on the transport of pesticides in the Kouris Dam (Cyprus)Global NEST J., 10(3), 350-358.

Marino M.A. (1973), Water-table fluctuations in semi-pervious stream-unconfined aquifer systems, Journal of Hydrology, 19(1), 43-52.

Moench A.F. and Barlow P.M. (2000), Aquifer response to stream-stage and recharge variations. I. Analytical step response functions, Journal of Hydrology, 230(3-4), 192-210.

Neuman S. (1981), Delayed drainage in a stream-aquifer system, Journal of Irrigation and Drainage Engineering, 107(IR4), 407-410.

Ostfeld A., Muzaffar E. and Lansey K.E. (1999), Analytical ground-water flow solutions for channel-aquifer interaction, Journal of Irrigation and Drainage Engineering, 125(4), 196-202.

Pipes L.A. and Harvill L.R. (1970), Applied mathematics for engineers and scientists, Third Edition, McGraw-Hill Book Company, New York.

Polubarinova-Kochina P.Ya. (1962), Theory of groundwater movement, Princeton University Press, Princeton, New Jersey.

Serrano S.E. (2003), Modelling groundwater flow under transient nonlinear free surface, Journal of Hydrologic Engineering, 8(3), 123-132.

Serrano S.E. and Workman S.R. (1998), Modeling transient stream/aquifer interaction with the non-linear Boussinesq equation and its analytical solution, Journal of Hydrology, 206(3-4), 245-255.

Singh S.K. (2003), Flow depletion of semipervious streams due to pumping, Journal of Irrigation and Drainage Engineering, 129(6), 449-453.

Singh S.K. (2004), Aquifer response to sinusoidal or arbitrary stage of semipervious stream, Journal of Hydraulic Engineering, 130(11), 1108-1118. 
Spanoudaki K., Nanou-Giannarou A. and Stamou A.I. (2006), Modelling pollutant transport is a streamaquifer system, in: Proceedings of IAHR-GW2006 International Conference on Groundwater Hydraulics in Complex Environments, Toulouse, France, June 12-14.

Spanoudaki K., Nanou-Giannarou A., Stamou A.I., Christodoulou G., Sparks T., Bockelmann B. and Falconer R.A. (2005), Integrated surface water-groundwater modelling, Global Nest J., 7(3), 281-295.

Stehfest H. (1970), Numerical inversion of Laplace transforms. Communications of the association for computing machinery, 13(1), 47-49.

Townley L.R. (1995), The response of aquifers to periodic forcing, Advances in Water Resources, 18(3), 125-146.

Van-de-Giesen N.C., Parlange J.Y. and Steenhuis T.S. (1994), Transient flow to open drains: comparison of linearized solutions with and without the Dupuit assumption, Water Resources Research, 30(11), 3033-3039.

Workman S.R., Serrano S.E. and Liberty K. (1997), Development and application of an analytical model of stream-aquifer interaction, Journal of Hydrology, 200(1-4), 149-163. 